OPEN ACCESS

Edited by:

Mieke Van Hemelrijck, King's College London,

United Kingdom

Reviewed by:

Hossain Jabbari,

Tehran University of Medical

Sciences, Iran

Azin Nahvijou,

Tehran University of Medical

Science, Iran

${ }^{*}$ Correspondence:

Peter D. Baade

peterbaade@cancerald.org.au

Specialty section:

This article was submitted to Cancer Epidemiology and Prevention,

a section of the journal

Frontiers in Oncology

Received: 24 September 2019

Accepted: 31 January 2020

Published: 28 February 2020

Citation:

Dasgupta P, Henshaw C, Youlden DR,

Clark PJ, Aitken JF and Baade PD

(2020) Global Trends in Incidence Rates of Primary Adult Liver Cancers:

A Systematic Review and

Meta-Analysis. Front. Oncol. 10:171.

doi: 10.3389/fonc. 2020.00171

\section{Global Trends in Incidence Rates of Primary Adult Liver Cancers: A Systematic Review and Meta-Analysis}

\author{
Paramita Dasgupta ${ }^{1}$, Chloe Henshaw ${ }^{1}$, Danny R. Youlden ${ }^{1,2}$, Paul J. Clark ${ }^{3,4,5}$, \\ Joanne F. Aitken ${ }^{1,2,6,7}$ and Peter D. Baade ${ }^{1,2,8 *}$ \\ ${ }^{1}$ Cancer Research Centre, Cancer Council Queensland, Brisbane, QLD, Australia, ${ }^{2}$ Menzies Health Institute Queensland, \\ Griffith University, Gold Coast, QLD, Australia, ${ }^{3}$ Faculty of Medicine, University of Queensland, Brisbane, QLD, Australia, \\ ${ }^{4}$ Mater Research Institute, Brisbane, QLD, Australia, ${ }^{5}$ Princess Alexandra Hospital \& Mater Hospital, Brisbane, QLD, \\ Australia, ${ }^{6}$ Institute for Resilient Regions, University of Southern Queensland, Toowoomba, QLD, Australia, ${ }^{7}$ School of Public \\ Health, University of Queensland, Brisbane, QLD, Australia, ${ }^{8}$ School of Mathematical Sciences, Queensland University of \\ Technology, Brisbane, QLD, Australia
}

Background: Primary liver cancer is a leading cause of cancer deaths worldwide. Global burden varies, reflecting geographical distribution of viral hepatitis. Our objective was to perform a systematic review and meta-analysis of published current trends in incidence of adult liver cancers and histological types worldwide.

Methods: This study used systematic searches of PubMed, Embase, CINAHL, and Web of Science databases for English-language peer-reviewed articles published from 1 January 2008 to 01 September 2019. Inclusion criteria were population-based studies of adult liver cancer patients with quantitative estimates of temporal trends in incidence for liver cancers and/or histological types. For multiple studies from the same geographical area, only the publication that reported the most recent trends for the same cancer type and population subgroup was included. Review was conducted per PRISMA guidelines. Two authors independently extracted data and critically assessed studies. Proposed contributors to observed trends were extracted from included articles. Study-specific estimates of the annual percentage change (APC) in incidence rates with 95\% confidence intervals (Cls) were pooled using random-effects meta-analysis models. Heterogeneity was measured using the $l^{2}$ statistics and publication bias evaluated using funnel plots and Egger's tests.

Results: Overall, 53 studies met the inclusion criteria, of which 31 were included in the meta-analysis. Overall, pooled APC estimates were $+0.8(95 \% \mathrm{Cl}-0.3,+2.0)$ for liver cancers combined, $+2.6(95 \% \mathrm{Cl}+1.2,+4.0)$ for hepatocellular carcinoma ( $\mathrm{HCC})$, and $+4.3(95 \% \mathrm{Cl}+2.5,+6.1)$ for intrahepatic cholangiocarcinoma. Subgroup analyses indicated increasing trends for liver cancers (APC +3.2, 95\% Cl +2.5, +3.9) and $\mathrm{HCC}(\mathrm{APC}+3.6,95 \% \mathrm{Cl}+2.9,+4.4)$ in the region of North America/Europe/Australia, whereas corresponding trends were decreasing (APC -1.7, 95\% $\mathrm{Cl}-2.2,-1.1$ ) and stable (APC $-0.7,95 \% \mathrm{Cl}-1.9,+0.5)$ in Asia, respectively. 
Conclusions: Incidence is increasing for adult liver cancers and HCC in Western countries, whereas trends are decreasing in the Asian region, although still remaining high. Our findings highlight the importance of viral hepatitis control and lifestyle interventions to reduce global liver cancer burden. Ongoing surveillance is also vital to detect early shifts in incidence trends.

Keywords: liver cancer, incidence, trends, hepatocellular carcinoma, systematic review, meta-analysis

\section{INTRODUCTION}

Primary liver cancer is the sixth most commonly diagnosed cancer and the fourth leading cause of cancer mortality worldwide, with an estimated 841,000 cases (9.3 cases per 100,000 person-years) and 782,000 deaths (8.5 deaths per 100,000 personyears) in 2018 (1). It is more common in men than in women (1). Outcomes are poor with an estimated 5-year net survival of 19\% (2009-2015) (2) and an average 19 years of life lost per death in the USA (3).

The two major histological types are hepatocellular carcinoma (HCC), which comprises around $75 \%$ of all liver cancer cases, and intrahepatic cholangiocarcinoma (ICC, about 12-15\%) (4). Liver cancer incidence rates vary from 5.1 per 100,000 personyears in Europe to 17.7 per 100,000 person-years in eastern Asia (5). This wide geographical variation primarily reflects regional differences in the prevalence of risk factors, especially for HCC (6). HCC generally occurs in the presence of liver disease or cirrhosis (7), and at least $60 \%$ of HCC cases worldwide are caused by viral hepatitis (8). Chronic hepatitis B virus (HBV), typically acquired at birth or early childhood, remains the leading cause in most high-risk HCC areas. In developed countries, the predominant etiology is more likely to be hepatitis $\mathrm{C}$ virus (HCV) infections acquired later in life (8). Other risk factors include dietary aflatoxin exposure, smoking, and high alcohol consumption, with nonalcoholic fatty liver disease (NAFLD) associated with obesity and diabetes increasingly emerging as a key contributor in the USA and other Western countries $(6,7)$.

Compared to HCC, relatively little is known about the etiology of ICC, especially in Western countries. Commonly cited risk factors include cirrhosis, viral hepatitis, primary sclerosing cholangitis, and liver fluke infections (in Asia) $(9,10)$.

Up-to-date accurate population-based data on cancer incidence and associated trends over time are fundamental for understanding the future cancer burden and informing health care planning and resource allocation. In 2014, an estimated $71 \%$ of all incident liver cancers diagnosed in the USA were attributable to potentially modifiable risk factors (11). A better understanding of the wide geographical variation in the global liver cancer burden, both within and between countries, may suggest novel targets for prevention strategies.

We performed a systematic review and meta-analysis to synthesize published evidence on contemporary trends in adult liver cancer incidence globally and to discuss the proposed contributors to the observed incidence trends. This review is intended to identify gaps in knowledge and contribute to the design of further etiological studies.

\section{METHODS}

\section{Definitions}

Primary liver cancer included the International Classification of Diseases for Oncology, 3rd Edition (ICD-O-3), or International Classification of Disease, Tenth Edition (ICD-10), site code C22. Histological types were typically defined as HCC (ICD-O-3 site code C22.0, morphology codes M8170-M8175), ICC (ICDO-3 site code C22.1, M8160), or combined hepatocellular cholangiocarcinoma (cHCC-CC, M8180).

Countries were grouped according to the 2019 United Nations Human Development Index (HDI) classification system (12) of developed (high/very high HDI) or developing (low/medium HDI).

\section{Clinical Question}

This review was conducted according to published PRISMA guidelines (13). The clinical question to guide the review was clearly defined following the structured PICOS framework and agreed upon before commencing the review process.

The PICOS question is: Among adults diagnosed with invasive liver cancer (Participants), was there any effect of calendar time (Intervention) from the start of the study time period (Comparisons) in the incidence rates (Outcomes) using population-based cohorts from cancer registries (Study design)?

\section{Searches}

The electronic databases PubMed, Embase, CINAHL, and Web of Science were systematically searched for all indexed articles from 1 January 2008 to focus on the most recent trends. Final searches were undertaken on 1 September 2019. Search strategies used selected subject headings and key words related to liver cancer, for example, "liver cancer," "liver neoplasms," "liver tumor," "hepatocellular carcinoma," "hepatic cancers," "hepatic tumors," and "intrahepatic cholangiocarcinoma", combined with ("incidence" and "trends" and "epidemiology") (Supplementary File 1). Reference lists of reviews and retrieved articles were checked to identify potentially relevant articles.

\section{Study Selection}

Studies were eligible if they met the following predetermined selection criteria:

1) The study is population based.

2) The study cohort included adults aged at least 15 years diagnosed with liver cancer and/or subgroups.

3) Outcome measure was incidence rates. 
4) Quantitative estimates of temporal trends in incidence rates were presented as percentage change over time.

The scope of the review was limited to English-language peerreviewed original research articles. Studies that only reported overall numbers or proportions of cases by time periods were excluded.

Multiple studies from the same geographical area that used the same data collection were screened to avoid including duplicate data in the review. Only the publication that reported the most recent incidence trends for the same liver cancer type and population subgroup (such as sex, age group, and race/ethnicity) was included.

The titles and abstracts of all unique articles identified by the queries were independently reviewed for their eligibility by two reviewers (CH and PD). Discrepancies were discussed and resolved through consensus. The full text of all articles deemed potentially relevant and those whose abstracts and titles provided insufficient information were then retrieved for more detailed evaluation by the same two reviewers. These were categorized as "include" or "exclude" while noting the reasons for exclusion. All decisions were compared and discussed. If necessary, another author was consulted (PB).

\section{Critical Appraisal}

A modified (14) version of the Newcastle-Ottawa Scale (NOS) (15), a risk-of-bias assessment tool for nonrandomized studies, was used for quality assessment. Studies were scored according to the extent that they met each of the nine assessed criteria using an ordinal scale to rate the risk of bias as 0 (high), 1 (intermediate), and 2 (low). Individual item scores were then summed to give a total score. Finally, the summary score for each article (average of the total scores from the two reviewers) was categorized into "high" (14-18), "moderate" (9-13.5), or "low" $(<9)$ quality. Studies were not excluded based specifically on their quality rating.

\section{Data Extraction and Synthesis}

For all included articles, one reviewer $(\mathrm{CH})$ collected data on bibliography [author(s), year, and title], study characteristics (location, time period, design, sample size, population, and liver cancer type), relevant statistical findings for the entire cohort and/or by population subgroups, and methodological details. A second reviewer (PD) independently checked the data extract against the original source for all included articles.

Incidence was reported as age-standardized rates, with standardization being commonly performed to world or US standard populations. While trends were presented as either the annual percentage change (APC) or average APC (AAPC) over time; for simplicity, the term APC is used throughout this review for both trend measures.

Incidence trends are first presented for all liver cancers combined and then separately for each histological type. Studies are sorted by sex and age group and then by country within each of the continents (Africa, Americas, Asia, Europe, and Oceania). Some studies are repeated either in the same table or across multiple tables. Only the most recent trend is considered for studies that reported changing trends over time.

In describing trends, the terms "increase" for positive point estimates and "decrease" for negative values were used when the reported trend estimate (APC) was statistically significant $(P<0.05)$. Otherwise, if the $95 \%$ confidence interval $(\mathrm{CI})$ included zero, the term "stable" was used. The term "short term" indicated that the time interval over which the trend was reported was $<12$ years, whereas "long term" describes trends over at least 12 years.

\section{Data Analysis}

The published trend estimates were pooled using randomeffects meta-analysis models (16) that allow for the inherent heterogeneity of observational studies. Only studies that also reported corresponding 95\% CI for point estimates and sufficiently homogeneous in terms of cohort characteristics (such as age group) were retained for the meta-analysis. We also compared included vs. excluded studies by looking at the distribution of the APC point estimates and geographical location.

The pooled outcome measures were stratified by cancer type: combined liver cancers, HCC, and ICC with additional subgroup analyses by three regional categories, namely, Asia; North America/Europe/Australia comprising USA, Canada, Australia, and European countries; and Africa/South America (less developed; countries in Africa and South America), performed if there were at least four studies per stratum. Summary estimates by smaller age groups, ethnicity, or race were not generated due to wide variability in their definitions.

Heterogeneity between study-specific estimates was assessed with the $Q$ and $I^{2}$ statistics (17). Publication bias was evaluated by funnel plots and Egger tests (18). Sensitivity analyses were conducted by assessing the impact on the summary measure of dropping specific studies. The influence of individual studies on the pooled estimates was assessed by repeating the meta-analysis, omitting one study at a time.

Forest plots were used for graphical presentation of metaanalysis results. All analyses were performed with Stata/SE version 15 (StataCorp, TX, USA).

\section{RESULTS}

\section{Study Selection}

As shown in a PRISMA diagram (Figure 1), a total of 700 articles were identified through the search queries, with an additional 26 records found through other sources. The removal of duplicates left 631 potentially eligible records, of which 455 were excluded after initial screening of the title and abstracts as they were not relevant to the study objectives. Of the remaining 176 fulltext articles that were evaluated for eligibility, 53 were retained for the review. The majority $(n=97)$ of the 123 excluded articles mentioned incidence trends in the abstract but did not specifically present quantitative estimates of these trends, while seven were based on analysis of estimated data from a secondary source and 19 articles were excluded to avoid duplication of data in the review (Supplementary File 2). 


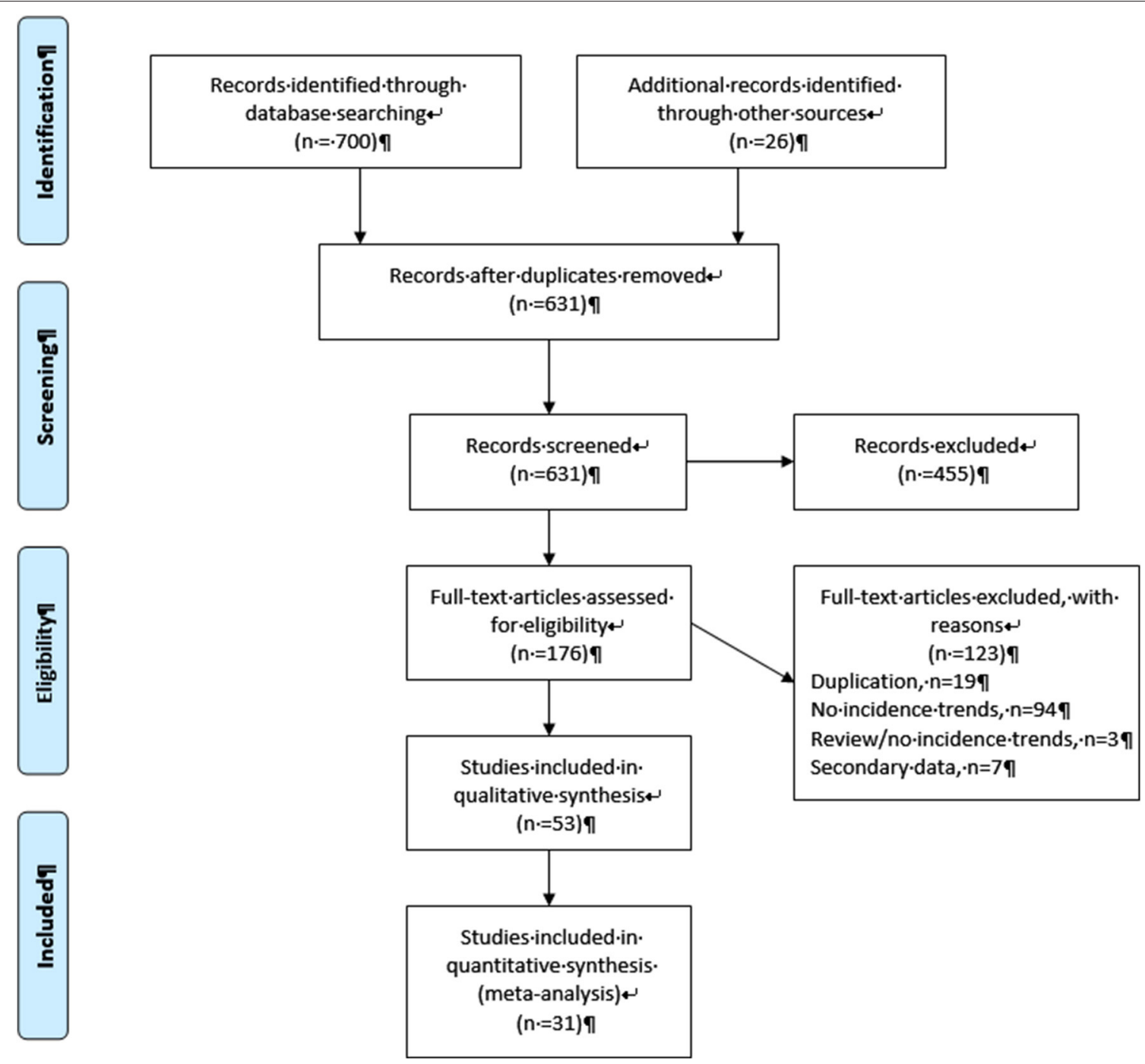

FIGURE 1 | Flow diagram of study selection for the systematic review.

\section{Study Characteristics Location}

Sixteen of the included studies were from the USA, followed by China (9), Australia (6), South Korea (3), Japan (3), Thailand (2), and the Netherlands (2). Three more studies were also from Europe (one each from Cyprus, France, and Spain) and Asia (one each from the Philippines, Taiwan, and Lebanon), two more from the Americas (Canada and Colombia), and four from Africa (one each from Botswana, Gambia, Mozambique, and Uganda).

\section{Cohort}

Data for all included studies were sourced from population-based state or nationwide cancer registries, with three also accessing other administrative databases.

The median cohort size was 10,170 [interquartile range (IQR): 789-34,695]. Of the 53 studies, 28 reported trends for all liver cancers, 15 for HCC only, 7 for ICC, 1 for both HCC and
ICC, and 1 for all liver cancers and HCC. One study looked at combined HCC and cholangiocarcinoma (cHCC-CC), a rare type of primary liver cancer.

The definition of "adult" varied in the included studies, with most including all ages above at least 15 years, although some restricted the upper boundary to $<80$ years. Eleven of 53 studies reported additional age-specific trends. Around half $(n=28)$ reported incidence trends for persons, of which 15 also presented sex-specific estimates, while the remaining studies $(n=25)$ only reported trends by sex. The only studies that reported trends by race and/or ethnicity were from the USA (10 of 16 studies).

\section{Outcome Measure}

All studies reported trends for age-standardized incidence rates in terms of APCs. Sixteen studies standardized age to the 2000 US population, 10 to the 1960 Segi World population, 13 to the 2000 world population, six to the 2001 Australian population, two to 
the European population, and 1 each to the 1985 Japanese, 2010 Korean, and 1996 Canadian populations. Three studies did not specify the standard population.

\section{Quality}

Twenty-two studies were rated as high quality, and the remaining 31 as moderate (Table 1, Supplementary Table 3.1). The median score was 13.5 (IQR: 13.0-14.0).

\section{Meta-Analysis}

Of the 53 studies, 31 (59\%) were retained for the meta-analysis. Excluded studies did not present 95\% CIs for the trend estimates $(n=16)$, only reported APCs by population subgroups $(n=5)$, or only reported on a rare liver cancer type $(n=1)$.

\section{Liver Cancers Combined}

Incidence trends varied by geographical region with 10 (four high quality and six moderate) of 11 included studies from North America/Europe/Australia reporting increasing trends and one (moderate quality) stable trends. In addition, of five studies from Africa/South America, three (moderate quality) described increasing trends, one (moderate quality) stable trends, and one (moderate quality) decreasing trends. By contrast, of 13 studies from Asia, 10 (two high quality and eight moderate) described decreasing incidence trends, two (one high quality and one moderate) stable trends, and one (moderate quality) increasing trends (Figure 2, Table 1, Supplementary Table 3.2).

One study reported decreasing trends in Botswana (19) and another increasing incidence in Uganda (22) among persons until 2008. Moreover, rates remained stable over two decades to mid2000s among males but increased among females in the Gambia (20), whereas corresponding trends were stable among both sexes in Mozambique (21).

All six studies from the USA consistently reported increasing incidence between 2011 and 2015 (28) or over recent decades (23-27). These increases were evident among persons $(23,24,26)$ and by sex $(23,25,27,28)$. In Colombia, trends increased in males but were stable among females from 2008 to 2012 (29). Among both males and females in Cyprus (43), France (44), and the Netherlands (45), incidence increased over one to two decades until the 2000s but was stable in Spain (46). One study in Australia reported increasing long-term trends among persons (and by sex) until 2014 (47).

In contrast, six Chinese studies reported decreasing liver cancer incidence rates among males, females, or persons over the past one to three decades $(30-34,37)$ with two more $(35,36)$ describing stable trends from around 2000. Two studies from Japan $(38,39)$ and one from South Korea (40) also reported decreasing incidence across both sexes over recent decades, consistent with the decrease in the Philippines between 1983 and 2002 (42). However, sex-specific trends increased in Lebanon between 2003 and 2008 (41).

\section{Trends by Age}

Two studies from the USA reported that long-term trends increased over recent decades among adults $\geq 45$ years $(24,26)$, decreased among those aged 35-44 (24) or 40-44 (26), and remained stable among those younger (Table 2). In contrast, incidence rates decreased across all age groups among persons aged 75 or younger over the past 10 years until around 2014 in China $(31,37)$.

\section{Summary Estimates}

The pooled APC estimate for liver cancers combined was $+0.8(95 \%$ CI $-0.3,+2.0)$ over 16 retained studies (25 APC estimates as some studies reported estimates separately for males and females). However, there was high $\left(I^{2}=98.6 \%\right)$ and significant $(Q=1,682, P<0.001)$ heterogeneity among the studies (Figure 3), although limited publication bias was evident based on the Egger test $(P=0.07)$ and funnel plot analysis (Supplementary Figure 4.1). Summary estimates from regional subgroup analysis however indicated increasing trends (APC $+3.2,95 \% \mathrm{CI}+2.5,+3.9$ ) for North America/Europe/Australia and stable trends (APC +1.0, 95\% CI -0.4, +2.3) for Africa/South America, whereas trends decreased in Asia (APC $-1.7,95 \%$ CI $-2.2,-1.1$ ). While heterogeneity remained (North America/Europe/Australia: $Q=117, P<0.001, I^{2}=76.3 \%$; Africa/South America: $Q=30, P<0.001, I^{2}=93.2 \%$; Asian $Q$ $\left.=30, P<0.001, I^{2}=76.5 \%\right)$, no publication bias was detected. Sensitivity analysis (results not shown) indicated that estimates were not sensitive to the inclusion/exclusion of individual studies.

\section{Hepatocellular Carcinoma}

Of the 13 studies from non-Asian countries (all from North America/Europe/Australia), 11 (eight high quality and three moderate) reported increasing incidence rates, one (high quality) stable, and one (moderate quality) decreasing trends, whereas three (of four) studies from Asia (one high quality and two moderate) described stable and/or decreasing trends while one (high quality) noted an increase (Figure 2, Table 1, Supplementary Table 3.3).

Five studies from the USA and one from Canada all reported increasing short-term (48) or long-term trends until the early 2000s (54) or later $(49,50,52,53)$. This pattern was evident among persons $(48,50,52,53)$ and/or by sex $(49,52-54)$ with only one study (48) noting increasing short-term incidence for males but a stable trend among females. In addition, one study described a short-term stable trend among persons from 2010 to 2015 in the USA (51). Incidence rates increased in males but were stable among females (and persons) over two decades until 2009 in the Netherlands (45). Two Australian studies also reported increasing long-term trends among both males and females until around $2013(59,63)$ although another found that incidence increased among males but remained stable in females from 1996 to 2011 (61).

In contrast, trends decreased among males but remained stable among females from 1974 to 2005 in China (55), were stable among persons (and by sex) in Taiwan from 2003 to 2011 (57), decreased among both males and females (<69 years, 1981-2003) in Japan (56), and were stable among males (2007-2013) while increasing among females (1989-2013) in Thailand (58). 
TABLE 1 | Summary of included studies by study quality and overall incidence trends for the most recent time periods by sex for liver cancers combined and histological types.

\begin{tabular}{|c|c|c|c|c|c|c|c|c|}
\hline References $^{a}$ & Location & Quality $^{\text {b }}$ & \multicolumn{2}{|c|}{ Persons } & \multicolumn{2}{|c|}{ Males } & \multicolumn{2}{|c|}{ Females } \\
\hline \multicolumn{9}{|l|}{ Africa } \\
\hline Dryden-Peterson et al. (19) & BOS & Moderate & 2003-2008 & & NR & NR & NR & NR \\
\hline Mutyaba et al. (22) & Kampala, UGA & Moderate & 1999-2008 & & NR & NR & NR & NR \\
\hline \multicolumn{9}{|l|}{ Americas (North America) } \\
\hline Melkonian et al. (23) & $\mathrm{USA}^{h, i}$ & High & 1999-2009 & & 1999-2009 & & 1999-2009 & \\
\hline Polednak (24) & $\mathrm{USA}^{h, j}$ & Moderate & 1999-2009 & & NR & NR & NR & \\
\hline Torre et al. (27) & USA ${ }^{o, p}$ & Moderate & NR & NR & 2003-2012 & & 2003-2012 & \\
\hline Ward et al. (28) & USA & High & NR & NR & 2011-2015 & & 2011-2015 & \\
\hline \multicolumn{9}{|l|}{ Americas (South America) } \\
\hline Bravo et al. (29) & COL & Moderate & NR & NR & 2008-2012 & & 2008-2012 & \\
\hline \multicolumn{9}{|l|}{ Asia } \\
\hline Chen et al. (30) & $\mathrm{CHN}$ & High & NR & NR & 2000-2011 & & 2008-2011 & \\
\hline Li et al. (31) & $\mathrm{GZ}, \mathrm{CHN}$ & Moderate & 2004-2015 & & 2004-2015 & & 2004-2015 & \\
\hline Li et al. (32) & $\mathrm{SH}, \mathrm{CHN}$ & High & 2002-2015 & 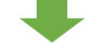 & $N R$ & NR & NR & NR \\
\hline Ito et al. (38) & Osaka, JPN & Moderate & 1998-2007 & $\zeta$ & 1998-2007 & & 1998-2007 & \\
\hline Katanoda et al. (39) & $\begin{array}{l}\text { Yamagata, Fukui, } \\
\text { and Nagasaki, JPN }\end{array}$ & Moderate & NR & $N R$ & $1992-2010$ & & 1995-2010 & \\
\hline Jung et al. (40) & KOR & Moderate & 1999-2012 & & 1999-2012 & & 1999-2012 & \\
\hline Shamseddine et al. (41) & LEB & Moderate & $N R$ & NR & 2003-2008 & & 2003-2008 & \\
\hline Medina et al. (42) & $\mathrm{PHL}$ & Moderate & NR & NR & 1983-2002 & & 1983-2002 & \\
\hline \multicolumn{9}{|l|}{ Europe } \\
\hline Cooter et al. (43) & CYP & Moderate & NR & $N R$ & 1998-2008 & & 1998-2008 & \\
\hline Lepage et al. (44) & FRA & Moderate & NR & NR & 1980-2000 & & 1980-2000 & \\
\hline Witjes et al. (45) & NLD & Moderate & NR & NR & 1989-2009 & & 1989-2009 & \\
\hline Clèries et al. (46) & ESP & Moderate & NR & NR & 2000-2007 & & 2000-2007 & \\
\hline
\end{tabular}


TABLE 1 | Continued

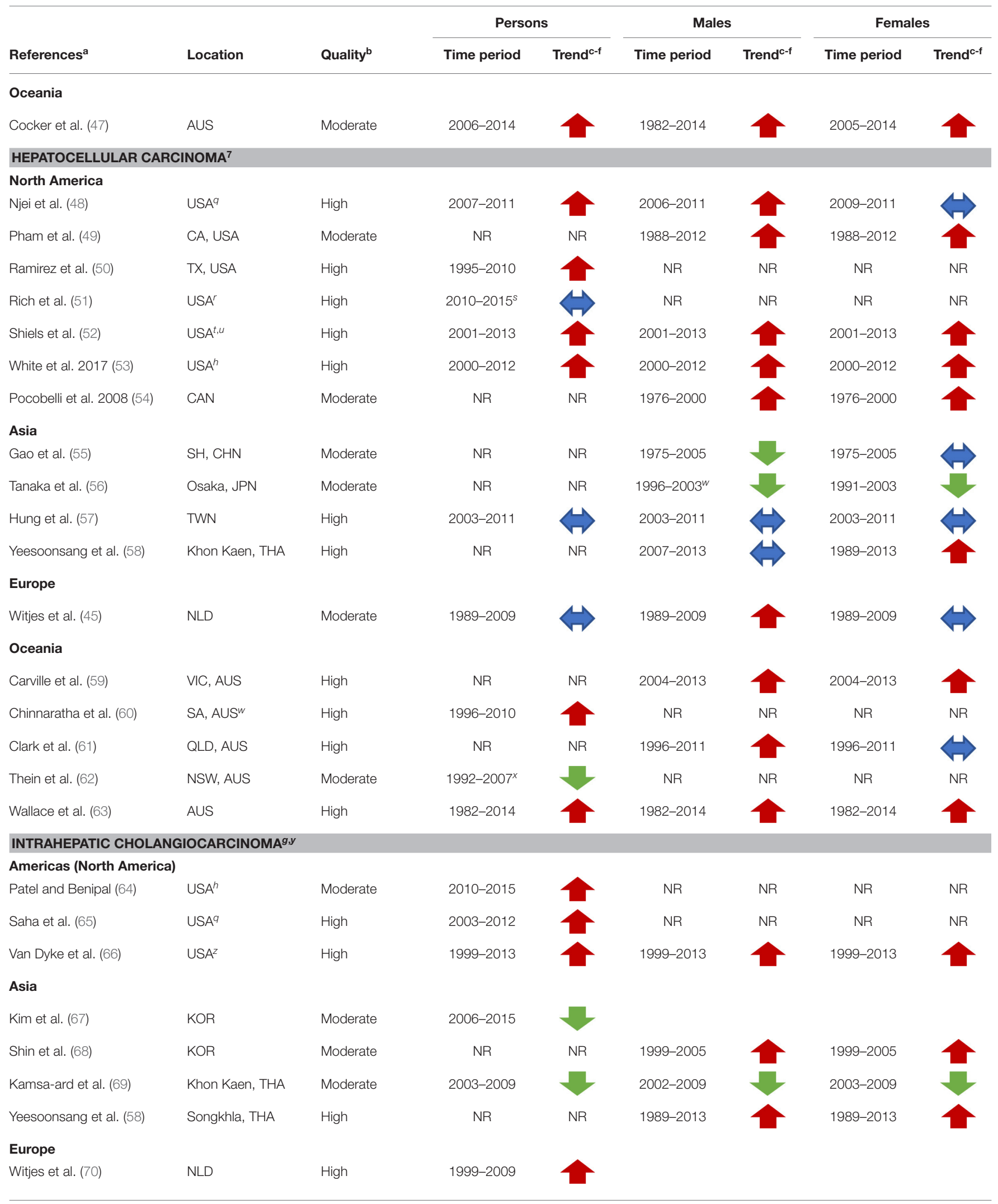




\begin{tabular}{|c|c|c|c|c|c|c|c|c|}
\hline References $^{a}$ & Location & Quality $^{b}$ & \multicolumn{2}{|c|}{ Persons } & \multicolumn{2}{|c|}{ Males } & \multicolumn{2}{|c|}{ Females } \\
\hline Wang et al. (71) & USA & High & 2000-2014 & & 2000-2014 & & NR & NR \\
\hline
\end{tabular}

MOZ, Mozambique; NLD, Netherlands; NR, Not reported, NSW, New South Wales; PHL, Philippines; QLD, Queensland; SA, South Australia; SH, Shanghai; SZ, Shenzhen; THA, Thailand; TJ, Tianjin; TWN, Taiwan; TX, Texas; UGA, Uganda; USA, United States; VIC, Victoria.

${ }^{a}$ All studies included adults aged at least 20 years and over unless otherwise stated.

${ }^{b}$ Quality categories: high (score 14-18), moderate (score 9-13.5), or low (score <9); please refer to text for further details.

${ }^{c}$ Trends based on annual percentage change (APC) in age-standardized incidence rate. The APC is the annual increase or decrease in incidence trends over the specified time period.

${ }^{d}$ Negative APC values indicate a decreasing trend, whereas positive APC values indicate an increasing trend. Stable means that the $95 \%$ confidence interval does not include zero.

e Increasing trends indicated by a red arrow; decreasing by a green arrow; and stable trends by a blue arrow.

${ }^{f}$ Only incidence trends for the most recent time period shown.

${ }^{9}$ Adult liver cancers were defined according to the International Classification of Disease for Oncology, Third Edition (ICD-O-3), or International Classification of Disease, Tenth Edition (ICD-10), site code (C22) and histologically as hepatocellular carcinoma (HCC) (ICD-O-3 site code C22.0, morphology codes M8170-M8175), intrahepatic cholangiocarcinoma (ICC, ICD-O-3 site code C22.1, M8160), or combined hepatocellular cholangiocarcinoma (CHCC-CC, ICD-O-3 morphology code M8180).

${ }^{h}$ Based on population-based cancer incidence data from the United States Cancer Statistics registry for all 50 states in the USA and the District of Colombia.

iIncidence trends reported for non-Hispanic Whites and non-Hispanic American Indian/Alaska Native. Trends increased for both groups.

iTrends increased for persons aged 55-64 years, decreased for those aged 35-44 years, and was stable for those aged 15-34 years.

${ }^{k}$ Based on population-based cancer incidence data from the North American Association of Central Cancer Registries database for 47 states and the District of Puerto Rico in the USA. IIncidence trends reported for non-Hispanic Whites and Hispanics. Trends increased for both groups.

${ }^{m}$ Based on population-based cancer incidence data from the North American Association of Central Cancer Registries database for 25 states in the USA.

${ }^{n}$ Trends reported by 5 -year age groups.

- Based on population-based cancer incidence data from the North American Association of Central Cancer Registries database for 24 states and one metropolitan area (Atlanta) in the USA.

PIncidence trends reported for non-Hispanic Whites and Asian/Pacific Islanders. Trends increased for non-Hispanic Whites and were decreasing/stable for Asian/Pacific Islanders.

${ }^{a}$ Based on population-based cancer incidence data from the Surveillance, Epidemiology and End Results (SEER 18) database covering 11 states and two metropolitan areas in the USA.

${ }^{r}$ Based on population-based cancer incidence data from the SEER 13 database covering six states and seven regions in the USA.

${ }^{s}$ Overall trend only. Trends decreased for persons aged 40-59 years and increased for those older.

${ }^{t}$ Based on data from the SEER/Medicare-linked database.

${ }^{u}$ Cohort included males and females aged 66-99 years.

vMales and females aged 50-69 years. Trends also decreased for males (1995-2003) and females (1997-2003) aged 60-69 and remained stable for those aged 70-79 years (2000-2003).

${ }^{w}$ Cohort included hepatitis B virus-infected cases.

${ }^{x}$ Increasing trends for hepatitis $C$ virus-infected cases; trend remained stable for hepatitis B virus-infected cases.

y Studies by Kamsa-ard et al. (69) and Yeesoonsang et al. (58) include all cholangiocarcinoma cases (CHCA, ICD-O-3 site codes C22.1 and C24.0).

${ }^{z}$ Based on population-based cancer incidence data from the North American Association of Central Cancer Registries database for 38 states in the USA.

Finally, while HCC incidence rates increased in Australia among the HBV-infected population from 1996 to 2010 in one study (60), corresponding trends were stable among those with HBV while decreasing among the HCV-infected population between 1992 and 2007 (62).

\section{Trends by Age}

Patterns for age-specific trends were mixed (Table 2). There was a suggestion of increasing trends among older adults ( $\geq 60$ years) in the USA (49-53), whereas they decreased (53) for persons aged $35-49$ years and were stable for younger age groups (53) over at least 10 years from 2000 onwards. One study reported that incidence rates had decreased among both younger ( $40-49$ years) and middle-aged $(49-53,55,57,59,61,63)$ adults since around mid-2000s to 2015 (51).

Age-specific rates increased by sex for those aged $>50$ years but only among younger males in Canada from 1976 to 2000 (54), while in the Netherlands, long-term trends (until 2009) increased among both males and females $<60$ years, whereas for those older, they increased among males but were stable for females (45). In contrast, rates decreased between 1981 and 2003 among both males and females $<69$ years of age in Japan but were stable among those aged 70-79 (56). In Taiwan, short-term trends decreased among persons $<65$ years but increased for those older between 2000 and 2003 (57). One Australian study described increasing long-term trends among persons aged at least 50 years (stable for ages 45-49) (63), whereas another reported increasing trends for males and stable trends for females across all age groups (61).

\section{Summary Estimates}

The summary estimate of the APCs $(+2.6,95 \%$ CI $+1.2,+4.0)$ over 13 studies (19 findings) for HCC indicated increasing incidence trends. High $\left(I^{2}=99.3 \%\right)$ and significant $(Q=2438$, $P<0.001$ ) heterogeneity was evident (Figure 4). No publication bias was detected (Egger $P=0.78$, Supplementary Figure 4.1). Subgroup analysis indicated increasing trends for North America/Europe/Australia ( $\mathrm{APC}+3.6,95 \% \mathrm{CI}+2.9,+4.4)$ and stable trends for Asia (APC $-0.7,95 \%$ CI $-1.9,+0.5$ ). While high and significant heterogeneity remained (North America/Europe/Australia: $Q=300, P<0.001, I^{2}=95.7 \%$; Asian: $\left.Q=28, P<0.001, I^{2}=85.7\right)$, no publication 


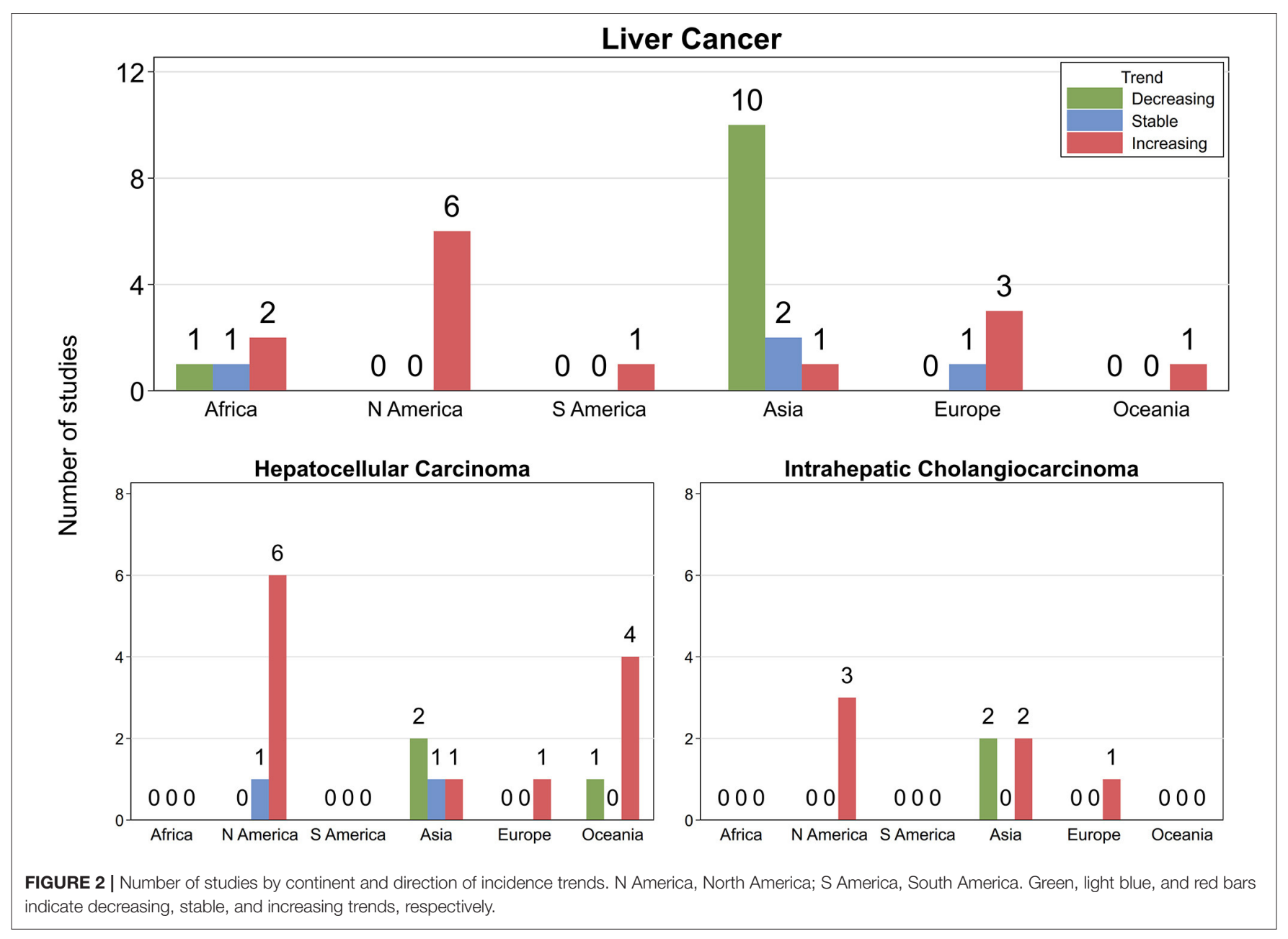

bias was detected when studies were stratified by region. Summary estimates were not sensitive to specific studies (results not shown).

\section{Intrahepatic Cholangiocarcinoma}

Six (four high and two moderate quality) of the eight included studies reported increasing trends, and two (both moderate quality) found decreasing trends (Figure 2, Table 1, Supplementary Table 3.4). All three studies from the USA (6466) and one from the Netherlands (70) described increasing short- or long-term trends among persons over recent decades until at least the late 2000s. While sex-specific rates increased from 1999 to 2005 (68) in South Korea, another study from the same country reported decreasing trends among persons over the decade until 2015 (67). Similarly, one study from Thailand (58) reported increasing long-term trends among both males and females over two decades until 2013, and another reported decreasing trends from 2003 to 2009 (69).

\section{Trends by Age}

While long-term trends increased across all ages in the USA until 2013 (66), they were stable among all age groups except those aged 45-59 years, for whom they increased from 1989 to 2009 in the Netherlands (70) (Table 2).

\section{Summary Estimates}

For ICC, the pooled estimate of $+4.3(95 \%$ CI $+2.5,+6.1)$ from four retained studies indicated large increases in incidence trends. There was high $\left(I^{2}=79.1 \%\right)$ and significant heterogeneity ( $Q=19.1, P=0.001$ ) between the studies (Figure 5); however, no evidence of publication bias was noted (Egger $P=0.68$, Supplementary Figure 4.1). Trend patterns did not change during the sensitivity analysis. Summary estimates by region were not performed due to an insufficient number of studies.

\section{Combined Hepatocellular Cholangiocarcinoma}

One study reported an increase in the incidence of cHCC-CC among both males and females over recent decades until 2014 in the USA (71).

Trends by Race and/or Ethnicity (USA Only) Two studies found increasing liver cancer rates overall for each analyzed racial/ethnic group $(23,25)$ while another reported increasing trends among non-Hispanic Whites for 
TABLE 2 | Summary of the most recent liver cancer incidence trends for included studies that present additional trend estimates by age or age and sex.

\begin{tabular}{|c|c|c|c|c|c|c|}
\hline \multirow[t]{2}{*}{ References } & \multirow{2}{*}{ Location } & \multirow{2}{*}{$\begin{array}{c}\text { Age } \\
\text { group } \\
\text { (years) }^{a}\end{array}$} & \multirow{2}{*}{$\begin{array}{c}\text { Time } \\
\text { period }\end{array}$} & \multicolumn{3}{|c|}{ Trend $^{b, c, d, e}$} \\
\hline & & & & Persons & Males & Females \\
\hline \multicolumn{7}{|c|}{ LIVER CANCERS COMBINED 6} \\
\hline \multicolumn{7}{|c|}{ Americas (North America) } \\
\hline Polednak (24) & USA $^{g}$ & $15-34$ & 1999-2009 & & NR & NR \\
\hline Polednak (24) & USA $^{g}$ & $35-44$ & 1999-2009 & & NR & NR \\
\hline Polednak (24) & $\mathrm{USA}^{g}$ & $45+$ & 1999-2009 & & NR & NR \\
\hline Sung et al. (26) & USA $^{h}$ & $25-39$ & 1995-2014 & & NR & NR \\
\hline Sung et al. (26) & $U_{S A}^{h}$ & $40-44$ & 1995-2014 & & NR & NR \\
\hline Sung et al. (26) & $U_{S A}^{h}$ & $45-84$ & 1995-2014 & & NR & NR \\
\hline \multicolumn{7}{|l|}{ Asia } \\
\hline Zheng et al. (37) & $\mathrm{CHN}$ & $0-79$ & 2000-2014 & & NR & NR \\
\hline Zheng et al. (37) & $\mathrm{CHN}$ & $80+$ & 2000-2014 & & NR & NR \\
\hline Li et al. (31) & $\mathrm{SH}, \mathrm{CHN}$ & $0-74$ & 2004-2015 & & NR & NR \\
\hline Li et al. (31) & $\mathrm{SH}, \mathrm{CHN}$ & $75+$ & 2004-2015 & & NR & NR \\
\hline \multicolumn{7}{|c|}{ HEPATOCELLULAR CARCINOMA ${ }^{6}$} \\
\hline \multicolumn{7}{|c|}{ Americas (North America) } \\
\hline Pham et al. (49) & CA, USA & 40-69 & 1988-2012 & & & \\
\hline Pham et al. (49) & CA, USA & $70+$ & $1988-2012$ & & & \\
\hline Ramirez et al. (50) & TX, USA & $50-59$ & 1995-2010 & & NR & $\mathrm{NR}$ \\
\hline Ramirez et al. (50) & TX, USA & $60-69$ & 1995-2010 & & $\mathrm{NR}$ & $\mathrm{NR}$ \\
\hline Ramirez et al. (50) & TX, USA & $70+$ & 1995-2010 & & $\mathrm{NR}$ & $\mathrm{NR}$ \\
\hline Rich et al. (51) & USA $^{i}$ & $40-59^{a}$ & 2009-2015 & & NR & $\mathrm{NR}$ \\
\hline Rich et al. (51) & USA $^{i}$ & $60-69$ & 2004-2015 & & $\mathrm{NR}$ & $\mathrm{NR}$ \\
\hline Rich et al. (51) & USA $^{i}$ & $70+$ & 1992-2015 & & $\mathrm{NR}$ & $\mathrm{NR}$ \\
\hline Shiels et al. (52) & USA & $66-75$ & 2001-2013 & & NR & NR \\
\hline Shiels et al. (52) & USA & $76-85$ & 2001-2013 & & NR & $\mathrm{NR}$ \\
\hline Shiels et al. (52) & USA & $86+$ & 2001-2013 & & $N R$ & NR \\
\hline White et al. (53) & $\mathrm{USA}^{g}$ & 20-34 & 2000-2012 & & NR & NR \\
\hline White et al. (53) & $\mathrm{USA}^{g}$ & $35-49$ & 2000-2012 & & $\mathrm{NR}$ & NR \\
\hline White et al. (53) & $\mathrm{USA}^{g}$ & $50+$ & 2000-2012 & & NR & NR \\
\hline Pocobelli et al. (54) & CAN & $20-49$ & 1976-2000 & & & \\
\hline Pocobelli et al. (54) & CAN & $50+$ & 1976-2000 & & & \\
\hline \multicolumn{7}{|l|}{ Asia } \\
\hline Hung et al. (57) & TWN & $15-64$ & 2000-2003 & & NR & NR \\
\hline Hung et al. (57) & TWN & $65+$ & 2000-2003 & & NR & $\mathrm{NR}$ \\
\hline Tanaka et al. (56) & $\begin{array}{l}\text { Osaka, } \\
\text { JPN }\end{array}$ & $50-69$ & $1981-2003$ & & & \\
\hline Tanaka et al. (56) & $\begin{array}{l}\text { Osaka, } \\
\text { JPN }\end{array}$ & $70-79$ & 1981-2003 & & & \\
\hline
\end{tabular}

(Continued)
TABLE 2 | Continued

\begin{tabular}{|c|c|c|c|c|}
\hline \multirow[t]{2}{*}{ References } & \multirow[t]{2}{*}{ Location } & \multirow{2}{*}{$\begin{array}{c}\text { Age } \\
\text { group } \\
\text { (years) }^{1}\end{array}$} & \multirow{2}{*}{$\begin{array}{c}\text { Time } \\
\text { period }\end{array}$} & Trend ${ }^{2,3,4,5}$ \\
\hline & & & & Persons Males Females \\
\hline
\end{tabular}

\section{Europe}

Witjes et al. (45) NLD

Witjes et al. (45) NLD

$<60 \quad 1989-2009 \quad N R$

\section{Oceania}

Clark et al. (61)

60+ 1989-2009 NR

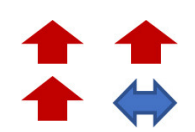

Clark et al. (61)

QLD, AUS ～<50 1996-2011

Clark et al. (61)

QLD, AUS 50-69 1996-2011

$N R$

Wallace et al. (63) AUS

QLD, AUS 70+ 1996-2011 NR
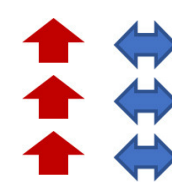

Wallace et al. (63) AUS

45-49 1982-2014

$50+\quad 1982-2014$

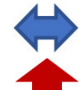

NR NR

\section{INTRAHEPATIC CHOLANGIOCARCINOMA ${ }^{6}$}

Americas (North America)

Van Dyke et al. (66) USA ${ }^{11}$

Van Dyke et al. (66) USA ${ }^{11}$

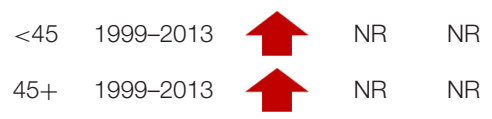

Europe

Witjes et al. (70) NLD

Witjes et al. (70) NLD

Witjes et al. (70) NLD

$\begin{array}{cc}30-44 & 1989-2009 \\ 45-59 & 1989-2009 \\ 60+ & 1989-2009\end{array}$

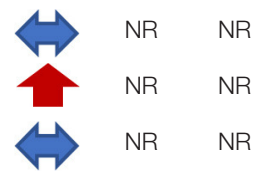

AUS, Australia; CA, California; CAN, Canada; CHN, China; NLD, Netherlands; NR, Not reported; QLD, Queensland; SH, Shanghai; TWN, Taiwan; TX, Texas; USA, United States. ${ }^{1}$ Only age groups for which incidence trends were reported are presented. Hence, for some studies, only certain age groups are shown.

${ }^{2}$ Trends based on annual percentage change (APC) in age-standardized incidence rate. The APC is the annual increase or decrease in incidence trends over the specified time period.

${ }^{3}$ Negative APC values indicate a decreasing trend, whereas positive APC values indicate an increasing trend. Stable means that the $95 \%$ confidence interval does not include zero. ${ }^{4}$ Increasing trends indicated by a red arrow, decreasing trends by a green arrow, and stable trends by a blue arrow.

${ }^{5}$ Only incidence trends for the most recent time period shown.

${ }^{6}$ Adult liver cancers were defined according to the International Classification of Disease for Oncology, Third Edition (ICD-O-3), or International Classification of Disease, Tenth Edition (ICD-10), site code (C22) and histologically as hepatocellular carcinoma (HCC) (ICD-O-3 site code C22.0, ICD-O-3 morphology codes M8170-M8175) or intrahepatic cholangiocarcinoma (ICC, ICD-O-3 site code C22.1, M8160).

${ }^{7}$ Based on population-based cancer incidence data from the United States Cancer Statistics registry for all 50 states in the USA and the District of Colombia.

${ }^{8}$ Based on population-based cancer incidence data from the North American Association of Central Cancer Registries database for 25 states in the USA.

${ }^{9}$ Based on population-based cancer incidence data from the Surveillance, Epidemiology and End Results (SEER 13) database covering six states and seven regions in the USA.

${ }^{10}$ Based on data from the SEER/Medicare-linked database.

${ }^{11}$ Based on population-based cancer incidence data from the North American Association of Central Cancer Registries database for 38 states in the USA.

both sexes, whereas they decreased among Asian/Pacific Islander (API) men and were stable among API women (27) (Supplementary Table 3.5). Incidence trends over the most recent 5-year period (2011-2015) also increased among both males and females for six major racial and ethnic groups in the USA except Hispanic men and API women (both with stable trends) and API men (decreasing trends) (28). 


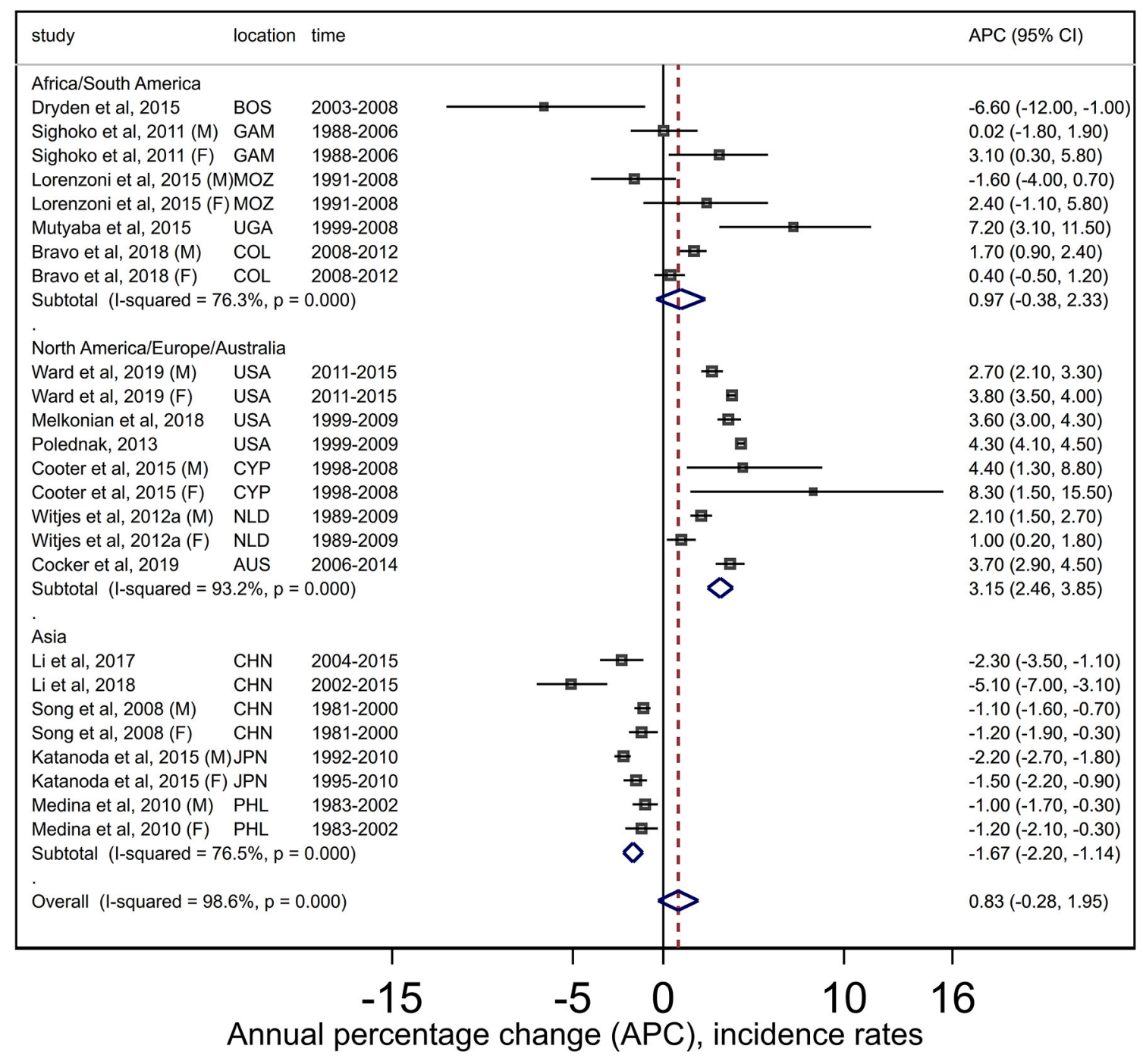

FIGURE 3 | Forest plots from meta-analysis of published incidence trends for adult liver cancers. AUS, Australia; BOS, Botswana; CYP, Cyprus; GAM, Gambia; COL, Colombia; CHN, China; F, Females; JPN, Japan; M, Males; MOZ, Mozambique; NLD, Netherlands; PHL, Philippines; UGA, Uganda; USA, United States.

Two studies reported increasing HCC incidence across all considered racial/ethnic groups $(49,50)$, and two others found increasing trends for all groups $(52,53)$ except APIs, where trends were either stable (52) or decreasing (53). Age-specific HCC incidence rates also increased from 1992 to 2015 among persons 60 years and older in all racial/ethnic groups except APIs aged 70-79 years, whereas they decreased among ages $40-59$ years of all races/ethnicities since the mid-2000s (51). Long-term trends for ICC increased across all racial/ethnic groups until 2013 (66).

\section{Comparison of Excluded and Included Studies in Meta-Analysis}

Visual inspection of box-and-whiskers plots for trend estimates from included and excluded studies in the meta-analysis (Supplementary Figure 4.2) showed that the median APC point estimate across studies excluded from the meta-analysis for liver cancers combined was skewed toward the right (lower or negative trends). However, the spread of the data was comparable between these two groups. For HCC and ICC, the median for the included and excluded studies was positive. Moreover, for all liver cancers (but not the two subtypes), a greater percentage of studies from the Asian region was excluded compared to non-Asian studies (62 vs. 38\%, respectively-see Supplementary Figure 4.3).

\section{DISCUSSION}

\section{Summary of Main Findings}

Our comprehensive systematic review found that the incidence rates for adult liver cancers combined and for HCC, the most commonly diagnosed histological subtype (4), continue to increase in Western countries. In contrast, trends decreased or were stable over recent decades for several Asian countries. These geographical patterns were reflected in summary pooled 


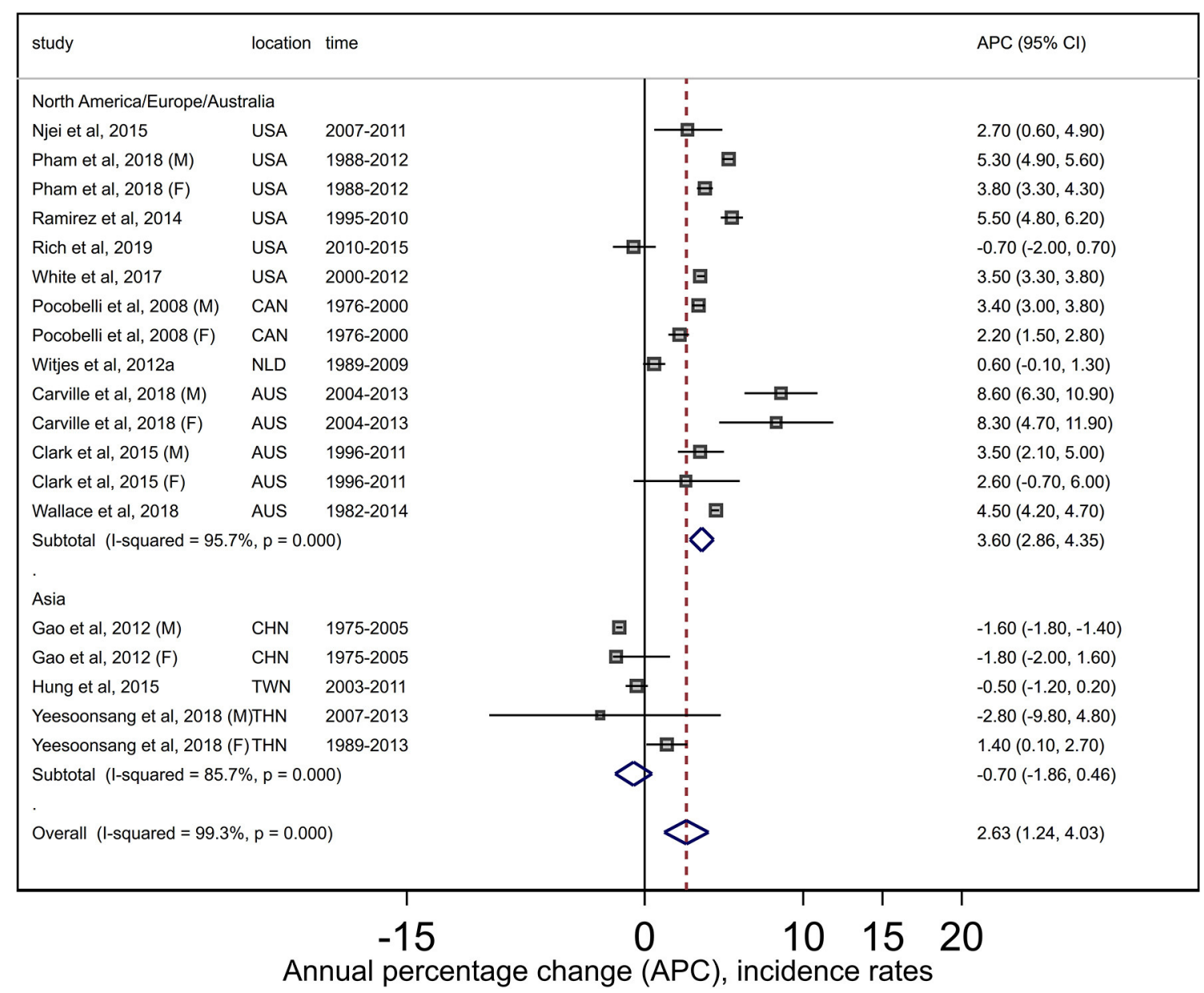

FIGURE 4 | Forest plots from meta-analysis of published incidence trends for adult hepatocellular carcinoma. AUS, Australia; CAN, Canada; CHN, China; F, Females; M, Males; NLD, Netherlands; TWN, Taiwan; THA, Thailand; USA, United States.

estimates from random-effects meta-analysis (16), which indicated that while trends were increasing overall and in Western countries (North America/Europe/Australia region) for both combined liver cancer and HCC, corresponding rates decreased or were stable in Asia, respectively. The different patterns may reflect geographical variation in the ratio of liver cancers attributable to HBV and $\mathrm{HCV}$, with $\mathrm{HBV}$ being the leading etiology in Asia, whereas the opposite is true in the USA and other Western countries (8), hence the decrease of newly diagnosed HCC cases following the implementation of mass HBV immunization in countries like China and South Korea. Our results highlight the substantial variation in liver cancer incidence across countries and the need for ongoing monitoring of patterns for population subgroups within regions.

We found that incidence rates for ICC, which comprises 12$15 \%$ of all liver cancer cases (4), have increased over recent decades. Summary estimates were also suggestive of rapidly increasing trends for ICC. ICC remains, in large part, a clinical diagnosis (72), so increases in incidence rates of this cancer may reflect improved diagnostic techniques (72) and greater awareness among clinicians. This is especially so in Southeast
Asian countries where ICC is endemic due to liver fluke infections $(9,10)$. However, recognized risk factors for ICC only account for approximately half of diagnosed cases in Western countries (10); hence, it is possible that as yet unknown etiological risk factors may also be involved.

No publication bias was detected for any of the reported meta-analysis. Sensitivity analysis suggested that the presented summary estimates are unlikely to be chance findings. Pooled estimates need to be interpreted with some caution, however, given the different periods and cohort characteristics of the included studies.

\section{Geographical Burden of Liver Cancer}

Despite the temporal increase in liver cancer incidence in Western countries, incidence rates in Asian countries remain among the highest in the world (1). In 2018, around a quarter of all incident cases and deaths occurred in Asia, with China alone accounting for around half of the global burden (5). In addition, age-standardized rates among males and females in China were around three times higher than corresponding rates in the USA (males 27.6 vs. 10.4 per 100,000; females 9.0 vs. 3.4 per 


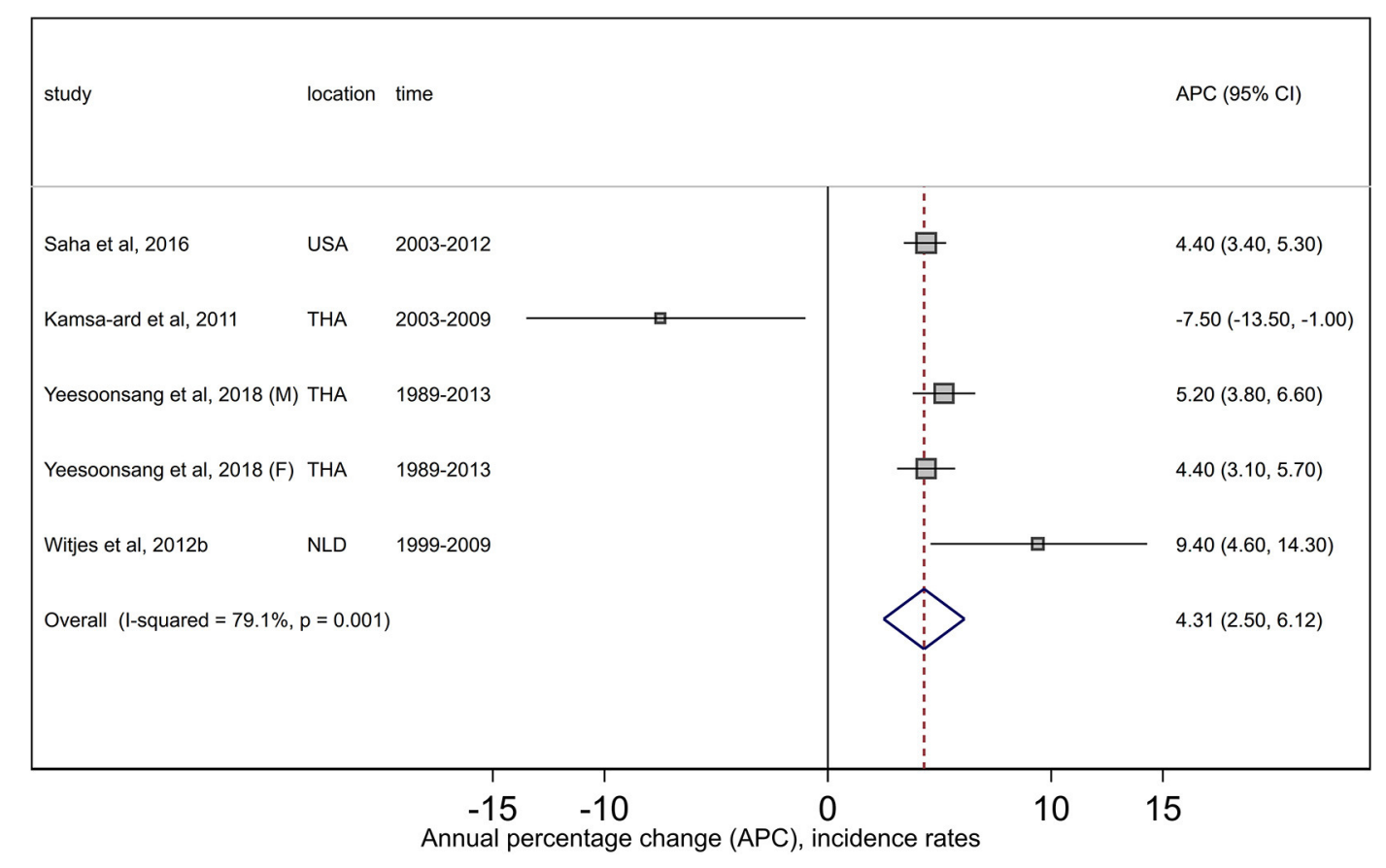

FIGURE 5 | Forest plots from meta-analysis of published incidence trends for intrahepatic cholangiocarcinoma. F, Females; M, Males; NLD, Netherlands; THA, Thailand; USA, United States.

100,000). These rates largely reflect the geographical variations in the prevalence of $\mathrm{HBV}$ infections, which have been estimated to be around $18 \%$ in China (73) compared to $<1 \%$ in the USA (74). Hence although declining liver cancer incidence trends in Asia are a positive development, they remain a major contributor to the global liver cancer burden. In addition, the high liver cancer mortality rate (1) translates to a heavy burden on health systems that may not have resources required for intensive surgical and clinical management of $\operatorname{HCC}(7,75)$.

\section{Proposed Drivers of Incidence Trends}

Viral hepatitis infections are the key driving etiology of liver cancers, especially HCC (8). High prevalence of chronic HBV among immigrants to Western countries from endemic HBV regions such as Asia (8) was widely proposed as a contributor to increasing incidence trends $(23,27,28,47,49,52-54,59-61,63$, 64). In the West, current increases in incidence also stem from a clinical lag time from HCV infection epidemics of the 1970s and 1980 s, with these individuals now evolving to liver cirrhosis with the associated higher HCC risk (23-28, 44, 45, 47, 49, 51-54, 59, 61, 63-65). Reducing exposures to these risk factors is logically the most effective way to lower the risk of developing liver cancer, and this was reflected in the most commonly cited reasons for decreasing incidence rates being mass HBV immunization (3034, 37, 42, 55, 57, 67), controlling HCV transmission (30, 39, $51,56)$, and efficacy of antiviral therapies for hepatitis infection $(19,27,37-39,56,57,62)$. New anti-HCV treatments widely available in Western countries offer effective cure of HCV even for patients with advanced liver disease and reduce HCC risk by $\sim 70 \%$ (76); however, their potential benefit has been hampered by lack of affordability and insurance coverage among certain population subgroups $(73,75,77)$.

Other commonly cited nonviral contributors to increasing trends, especially in Western countries, were obesity (20, 23$25,27,47,49-53,64-66)$, high alcohol consumption $(23,25,44$, $49,51-53,59,61,64,65)$, diabetes $(20,23-25,27,47,49-53,63-$ $66)$, and NAFLD $(44,45,47,49,51-53,59,61,63,66)$, all of which increase the risk of liver cancers $(4,6,73,78)$. Reported trends could also at least partially be an artifact of temporal changes in cancer coding and reporting practices $(58,68,70)$, imaging technology $(24,43-45,51,58-60,64,65,70)$, and screening $(27,45,51,55-57)$, reflecting the adoption of accepted guidelines for HCC screening and management $(79,80)$.

Several key risk factors for liver cancers are modifiable (7), including obesity, excessive alcohol use, smoking, and viral hepatitis infections, reflected in $71 \%$ of cases in the USA (11) being estimated to be potentially preventable. Many of the included studies highlighted the importance of continuing efforts to reduce the risks associated with viral hepatitis through primary (HBV vaccination) $(23,25,27,48,49,60)$ and secondary prevention efforts. The latter include screening of high-risk populations $(23,31,47,49,51-53,61)$ and ensuring equitable access to curative therapies for $\mathrm{HBV} / \mathrm{HCV}$ infections among all population subgroups $(23,32,37,47,48,52,53,59)$. However, even if incidence of HCV-related HCC decreases in the future due to improved treatments and better control $(75,81)$, this may be offset by the emerging etiological importance of NAFLD as a key risk factor $(77,82)$. The latter reflects the continuing increase in the global prevalence of obesity $(83,84)$ and diabetes $(84,85)$, two well-established risk factors for NAFLD (86). Hence, 
targeted strategies for promoting healthier lifestyles $(20,23,25$, $27,33,36,37,47,51-53,59,66)$ are also vital for reducing the global liver cancer burden. The challenge is in the development and implementation of successful strategies to achieve this goal $(7,75,77,87)$, which is especially important given the high mortality rates (1) and poor survival for liver cancer (88).

The consistently high and increasing liver cancer, and in particular HCC, incidence rates among middle-aged adults in the USA $(24,26,49,51-53)$ reflect the birth cohort effect related to HCV infection which peaked among Americans born between 1945 and 1965 through intravenous drug use during the 1960s-1980s (89). While not the primary focus of this review, racial and ethnic variations in liver cancer incidence rates in the USA were attributed at least partially to differences in the distribution of major risk factors and protective practices related to viral hepatitis control among different groups and over time $(25,27,50,53)$. For example, although APIs in the USA have had historically high liver cancer/HCC incidence rates, reflecting endemic HBV infectious among Asians, greater awareness and uptake of viral hepatitis screening and antiviral therapy may have contributed to generally decreasing trends since the mid-2000s (27, 51-53).

\section{Limitations}

Limitations included high heterogeneity between the retained studies for the meta-analyses and the underrepresentation of studies from high-incidence countries in Africa and Asia (except Eastern and Southeastern Asia). Notably, of 31 studies included in the calculation of the pooled estimates, only three (Mozambique, Gambia, and Uganda) were from developing countries as defined by the 2019 HDI classification (12).

Although multiple databases were searched with complex queries and reference lists of identified articles were also used to maximize the completeness of those included, we acknowledge that the search terms and criteria used as well as choice of citation databases could have unintentionally resulted in some relevant articles being excluded. Only peer-reviewed published studies in English were included; hence, this review could potentially be subject to language bias.

Wide temporal and demographical variability across included studies could have impacted between-study heterogeneity. Geographical variations in the availability of high-quality cancer registry data, which could influence the reported incidence trends, mean that comparisons between (and even within) countries must be interpreted cautiously (90). Another potential limitation is the differing standard populations used for generating the ASRs.

Around two-thirds ( $n=31,59 \%)$ of the 53 included studies were retained in the meta-analysis; however, comparison of the point trend estimates and geographical location between the included and excluded studies suggested that the former group was broadly representative of all reviewed studies. It is nonetheless possible that the summary trend estimates may have been overestimated given that estimates from the excluded studies tended to have a right-skewed distribution in comparison to the included studies. In addition, the limited information on plausible contributors in population-based cancer registries restricted the ability of the study authors to draw firm conclusions regarding the true drivers of the reported trends.

\section{CONCLUSIONS}

This review summarizes published estimates of global incidence trends in combined adult liver cancers by key histological types. In general, a continuing increase in incidence rates, especially among middle-aged adults, was evident across recent decades in several Western countries with historically low incidence rates. However, while trends decreased in several Asian countries, they still have the highest incidence rates worldwide, and absolute numbers remain very high. These findings highlight that liver cancer is likely to remain a major public health problem in the coming decades, albeit with a change in the distribution of cases worldwide. Demographic transition in countries where $\mathrm{HBV}$ is endemic offers significant hope to eventually curb the high mortality burden of HCC, though improvement is unlikely to be imminent. Emerging global trends in obesity and metabolic risk factors suggest that a new risk horizon for HCC is now evident in the West and looming in Asian and developing countries. Our findings also highlighted the impact of various public health strategies in reducing the incidence trends of viral hepatitis-related liver cancer. Design and implementation of evidence-based programs to reduce the global liver cancer burden, for example, through viral hepatitis control and lifestyle interventions, are a priority. Ongoing epidemiological surveillance is also vital to detect early shifts in incidence trends, particularly within high-risk population groups.

\section{DATA AVAILABILITY STATEMENT}

The raw data used in the meta analyses included in this article will be made available by the authors upon request.

\section{AUTHOR CONTRIBUTIONS}

$\mathrm{PB}, \mathrm{PD}, \mathrm{JA}$, and DY contributed to the design of the study. PB and $\mathrm{PD}$ coordinated the study. $\mathrm{PD}$ and $\mathrm{CH}$ conducted the literature searches and acted as reviewers. PD drafted the manuscript. PB contributed to the initial draft of the manuscript. $\mathrm{PB}, \mathrm{PD}, \mathrm{DY}$, JA, PC, and $\mathrm{CH}$ refined and approved the final version of the paper. Each author has participated sufficiently in the work and takes responsibility for appropriate portions of the content. All authors have read and have given final approval of the version to be published.

\section{SUPPLEMENTARY MATERIAL}

The Supplementary Material for this article can be found online at: https://www.frontiersin.org/articles/10.3389/fonc. 2020.00171/full\#supplementary-material 


\section{REFERENCES}

1. Bray F, Ferlay J, Soerjomataram I, Siegel RL, Torre LA, Jemal A. Global cancer statistics 2018: GLOBOCAN estimates of incidence and mortality worldwide for 36 cancers in 185 countries. CA Cancer J Clin. (2018) 68:394-424. doi: $10.3322 /$ caac. 21492

2. Howlader M, Noone AM, Krapcho M, Miller KD, Brest A, Yu MC, et al. SEER Cancer Statistics Review, 1975-2016. Bethesda, MD: National Cancer Institute (2019). Available online at: https://seer.cancer.gov/csr/1975_2016/ (accessed July 29, 2019).

3. Islami F, Miller KD, Siegel RL, Fedewa SA, Ward EM, Jemal A. Disparities in liver cancer occurrence in the United States by race/ethnicity and state. $C A$ Cancer J Clin. (2017) 67:273-89. doi: 10.3322/caac.21402

4. Petrick JL, McGlynn KA. The changing epidemiology of primary liver cancer. Curr Epidemiol Rep. (2019) 6:104-11. doi: 10.1007/s40471-01900188-3

5. Ferlay J, Ervik M, Lam F, Colombet M, Mery L, Piñeros M, et al. GLOBOCAN 2018, Global and Regional Estimates of the Incidence and Mortality for 36 Cancers Global Cancer Observatory: Cancer Today. Lyon: International Agency for Research on Cancer (2018). Available online at: https://gco.iarc. fr/today (accessed July1, 2019).

6. Kulik L, El-Serag HB. Epidemiology and management of hepatocellular carcinoma. Gastroenterology. (2019) 156:477-91.e1. doi: 10.1053/j.gastro.2018.08.065

7. Yang JD, Hainaut P, Gores GJ, Amadou A, Plymoth A, Roberts LR. A global view of hepatocellular carcinoma: trends, risk, prevention and management. Nat Rev Gastroenterol Hepatol. (2019) 16:589-604. doi: 10.1038/s41575-019-0186-y

8. de Martel C, Maucort-Boulch D, Plummer M, Franceschi S. World-wide relative contribution of hepatitis $\mathrm{B}$ and $\mathrm{C}$ viruses in hepatocellular carcinoma. Hepatology. (2015) 62:1190-200. doi: 10.1002/hep.27969

9. Clements O, Eliahoo J, Un Kim J, Taylor-Robinson SD, Khan SA. Risk factors for intrahepatic and extrahepatic cholangiocarcinoma: a systematic review and meta-analysis. J Hepatol. (2019) 72:95-103. doi: 10.1016/j.jhep.2019.09.007

10. Khan SA, Tavolari S, Brandi G. Cholangiocarcinoma: epidemiology and risk factors. Liver Int. (2019) 39(Suppl. 1):19-31. doi: 10.1111/liv.14095

11. Islami F, Goding Sauer A, Miller KD, Siegel RL, Fedewa SA, Jacobs EJ, et al. Proportion and number of cancer cases and deaths attributable to potentially modifiable risk factors in the United States. CA Cancer J Clin. (2018) 68:31-54. doi: $10.3322 /$ caac. 21440

12. United Nations Development Programme. Human Development Index Ranking 2019. New York (2019). Available online at: http://hdr.undp.org/ en/content/2019-human-development-index-ranking (accessed December 1, 2019).

13. Liberati A, Altman DG, Tetzlaff J, Mulrow C, Gotzsche PC, Ioannidis JP, et al. The PRISMA statement for reporting systematic reviews and meta-analyses of studies that evaluate healthcare interventions: explanation and elaboration. BMJ. (2009) 339:b2700. doi: 10.1136/bmj.b2700

14. Dasgupta P, Baade PD, Youlden DR, Garvey G, Aitken JF, Wallington I, et al. Variations in outcomes by residential location for women with breast cancer: a systematic review. BMJ Open. (2018) 8:e019050. doi: 10.1136/bmjopen-2017-019050

15. Wells G, Shea B, O'Connell D, Peterson J, Welch V, Losos M, et al. The Newcastle-Ottawa Scale. (NOS) for Assessing the Quality of Non-randomised Studies in Meta-analyses. (2016). Available online at: http://www.ohri.ca/ programs/clinical_epidemiology/oxford.asp (accessed May 2, 2018).

16. DerSimonian R, Laird N. Meta-analysis in clinical trials revisited. Contemp Clin Trials. (2015) 45(Pt A):139-45. doi: 10.1016/j.cct.2015.09.002

17. Higgins JP, Thompson SG, Deeks JJ, Altman DG. Measuring inconsistency in meta-analyses. BMJ. (2003) 327:557-60. doi: 10.1136/bmj.327.7414.557

18. Egger M, Davey Smith G, Schneider M, Minder C. Bias in metaanalysis detected by a simple, graphical test. BMJ. (1997) 315:629-34. doi: 10.1136/bmj.315.7109.629

19. Dryden-Peterson S, Medhin H, Kebabonye-Pusoentsi M, Seage GR, Suneja G, Kayembe MKA, et al. Cancer incidence following expansion of HIV treatment in Botswana. PLoS ONE. (2015) 10:e0135602. doi: 10.1371/journal.pone.0135602
20. Sighoko D, Curado MP, Bourgeois D, Mendy M, Hainaut P, Bah E. Increase in female liver cancer in the Gambia, West Africa: evidence from 19 years of population-based cancer registration (1988-2006). PLoS ONE. (2011) 6:e18415. doi: 10.1371/journal.pone.0018415

21. Lorenzoni C, Vilajeliu A, Carrilho C, Ismail MR, Castillo P, Augusto O, et al. Trends in cancer incidence in Maputo, Mozambique, 1991-2008. PLoS ONE. (2015) 10:e0130469. doi: 10.1371/journal.pone.0130469

22. Mutyaba I, Phipps W, Krantz EM, Goldman JD, Nambooze S, Orem J, et al. A population-level evaluation of the effect of antiretroviral therapy on cancer incidence in Kyadondo County, Uganda, 1999-2008. J Acquir Immune Defic Syndr. (2015) 69:481-6. doi: 10.1097/QAI.0000000000000620

23. Melkonian SC, Jim MA, Reilley B, Erdrich J, Berkowitz Z, Wiggins $\mathrm{CL}$, et al. Incidence of primary liver cancer in American Indians and Alaska Natives, US, 1999-2009. Cancer Causes Control. (2018) 29:833-44. doi: 10.1007/s10552-018-1059-3

24. Polednak AP. Surveillance and interpretation of trends in US age-specific incidence rates for primary liver cancer, in relation to the epidemic of hepatitis C infection. J Registry Manag. (2013) 40:115-21.

25. Siegel RL, Fedewa SA, Miller KD, Goding-Sauer A, Pinheiro PS, MartinezTyson D, et al. Cancer statistics for Hispanics/Latinos, 2015. CA Cancer J Clin. (2015) 65:457-80. doi: 10.3322/caac.21314

26. Sung H, Siegel RL, Rosenberg PS, Jemal A. Emerging cancer trends among young adults in the USA: analysis of a population-based cancer registry. Lancet Public Health. (2019) 4:e137-47. doi: 10.1016/S2468-2667(18)30267-6

27. Torre LA, Sauer AM, Chen MS, Jr., Kagawa-Singer M, Jemal A, Siegel RL. Cancer statistics for Asian Americans, Native Hawaiians, and Pacific Islanders, 2016: converging incidence in males and females. CA Cancer J Clin. (2016) 66:182-202. doi: 10.3322/caac.21335

28. Ward E, Sherman RL, Henley SJ, Jemal A, Siegel DA, Feuer EJ, et al. Annual Report to the Nation on the Status of Cancer, 1999-2015, featuring cancer in men and women ages 20-49. J Natl Cancer Inst. (2019) 111:1279-97. doi: $10.1093 /$ inci/djz106

29. Bravo LE, García LS, Collazos P, Carrascal E, Ramírez O, Collazos T, et al. Reliable information for cancer control in Cali, Colombia. Colomb Med. (2018) 49:23-34. doi: 10.25100/cm.v49i1.3689

30. Chen W, Zheng R, Baade PD, Zhang S, Zeng H, Bray F, et al. Cancer statistics in China, 2015. CA Cancer J Clin. (2016) 66:115-32. doi: 10.3322/caac.21338

31. Li K, Lin G, Li Y, Xu H. Time trends and patterns of primary liver cancer in Guangzhou from 2004 to 2015. Prec Radiat Oncol. (2017) 1:116-20. doi: 10.1002/pro6.30

32. Li X, Deng Y, Tang W, Sun Q, Chen Y, Yang C, et al. Urban-rural disparity in cancer incidence, mortality, and survivals in Shanghai, China, During 2002 and 2015. Front Oncol. (2018) 8:579. doi: 10.3389/fonc.2018.00579

33. Liu Z, Jiang Y, Fang Q, Yuan H, Cai N, Suo C, et al. Future of cancer incidence in Shanghai, China: predicting the burden upon the ageing population. Cancer Epidemiol. (2019) 60:8-15. doi: 10.1016/j.canep.2019.03.004

34. Song F, He M, Li H, Qian B, Wei Q, Zhang W, et al. A cancer incidence survey in Tianjin: the third largest city in China - Between 1981 and 2000. Cancer Causes Control. (2008) 19:443-50. doi: 10.1007/s10552-007-9105-6

35. Wang N, Zhu WX, Xing XM, Yang L, Li PP, You WC. Time trends of cancer incidence in urban Beijing, 1998-2007. Chin J Cancer Res. (2011) 23:15-20. doi: 10.1007/s11670-011-0015-5

36. Xu Z, Zhou H, Lei L, Li H, Yu W, Fu Z, et al. Incidence of cancer in Shenzhen, Guangdong Province during 2001-2015: a retrospective population-based study. Int J Environ Res Public Health. (2017) 14:E1137. doi: 10.3390/ijerph14101137

37. Zheng R, Qu C, Zhang S, Zeng H, Sun K, Gu X, et al. Liver cancer incidence and mortality in China: temporal trends and projections to 2030. Chin J Cancer Res. (2018) 30:571-9. doi: 10.21147/j.issn.1000-9604.2018.06.01

38. Ito Y, Ioka A, Nakayama T, Tsukuma H, Nakamura T. Comparison of trends in cancer incidence and mortality in Osaka, Japan, using an age-period-cohort model. Asian Pac J Cancer Prev. (2011) 12:879-88.

39. Katanoda K, Hori M, Matsuda T, Shibata A, Nishino Y, Hattori M, et al. An updated report on the trends in cancer incidence and mortality in Japan, 1958-2013. Jpn J Clin Oncol. (2015) 45:390-401. doi: 10.1093/jjco/hyv002

40. Jung KW, Won YJ, Kong HJ, Oh CM, Cho H, Lee DH, et al. Cancer statistics in Korea: incidence, mortality, survival, and prevalence in 2012. Cancer Res Treat. (2015) 47:127-41. doi: 10.4143/crt.2015.060 
41. Shamseddine A, Saleh A, Charafeddine M, Seoud M, Mukherji D, Temraz S, et al. Cancer trends in Lebanon: a review of incidence rates for the period of 2003-2008 and projections until 2018. Popul Health Metrics. (2014) 12:4. doi: 10.1186/1478-7954-12-4

42. Medina VM, Laudico A, Mirasol-Lumague MR, Brenner H, Redaniel MT. Cumulative incidence trends of selected cancer sites in a Philippine population from 1983 to 2002: a joinpoint analysis. Br J Cancer. (2010) 102:1411-4. doi: 10.1038/sj.bjc.6605640

43. Cooter M, Soliman AS, Pavlou P, Demetriou A, Orphanides C, Kritioti E, et al. Incidence and time trends of cancer in Cyprus over 11 years (1998-2008). Tumori. (2015) 101:8-15. doi: 10.5301/tj.5000204

44. Lepage C, Remontet L, Launoy G, Trétarre B, Grosclaude P, Colonna M, et al. Trends in incidence of digestive cancers in France. Eur J Cancer Prev. (2008) 17:13-7. doi: 10.1097/CEJ.0b013e32809b4cba

45. Witjes CDM, Karim-Kos HE, Visser O, Van Den Akker SAW, De Vries E, Ijzermans JNM, et al. Hepatocellular carcinoma in a low-endemic area: rising incidence and improved survival. Eur J Gastroenterol Hepatol. (2012) 24:450-7. doi: 10.1097/MEG.0b013e32835030ce

46. Clèries R, Esteban L, Borràs J, Marcos-Gragera R, Freitas A, Carulla M, et al. Time trends of cancer incidence and mortality in Catalonia during 1993-2007. Clin Transl Oncol. (2014) 16:18-28. doi: 10.1007/s12094-013-1060-y

47. Cocker F, Chien Yee K, Palmer AJ, de Graaff B. Increasing incidence and mortality related to liver cancer in Australia: time to turn the tide. Aust NZ J Public Health. (2019) 43:267-73. doi: 10.1111/1753-6405.12889

48. Njei B, Rotman Y, Ditah I, Lim JK. Emerging trends in hepatocellular carcinoma incidence and mortality. Hepatology. (2015) 61:191-9. doi: $10.1002 /$ hep. 27388

49. Pham C, Fong T-L, Zhang J, Liu L. Striking racial/ethnic disparities in liver cancer incidence rates and temporal trends in California, 1988-2012. J Natl Cancer Inst. (2018) 110:1259-69. doi: 10.1093/jnci/djy051

50. Ramirez AG, Munoz E, Holden AEC, Adeigbe RT, Suarez L. Incidence of hepatocellular carcinoma in Texas Latinos, 1995-2010: an update. PLoS ONE. (2014) 9:e99365. doi: 10.1371/journal.pone.0099365

51. Rich NE, Yopp AC, Singal AG, Murphy CC. Hepatocellular carcinoma incidence is decreasing among younger adults in the United States. Clin Gastroenterol Hepatol. (2019) 18:242-8.e5. doi: 10.1016/j.cgh.2019.04.043

52. Shiels MS, Engels EA, Yanik EL, McGlynn KA, Pfeiffer RM, O’Brien TR. Incidence of hepatocellular carcinoma among older Americans attributable to hepatitis C and hepatitis B: 2001 through 2013. Cancer. (2019) 125:2621-30. doi: $10.1002 /$ cncr.32129

53. White DL, Thrift AP, Kanwal F, Davila J, El-Serag HB. Incidence of hepatocellular carcinoma in all 50 United States, from 2000 through 2012. Gastroenterology. (2017) 152:812-20.e5. doi: 10.1053/j.gastro.2016.11.020

54. Pocobelli G, Cook LS, Brant R, Lee SS. Hepatocellular carcinoma incidence trends in Canada: analysis by birth cohort and period of diagnosis. Liver Int. (2008) 28:1272-9. doi: 10.1111/j.1478-3231.2008.01704.x

55. Gao S, Yang WS, Bray F, Va P, Zhang W, Gao J, et al. Declining rates of hepatocellular carcinoma in urban Shanghai: incidence trends in 1976-2005. Eur J Epidemiol. (2012) 27:39-46. doi: 10.1007/s10654-011-9636-8

56. Tanaka $\mathrm{H}$, Imai $\mathrm{Y}$, Hiramatsu $\mathrm{N}$, Ito $\mathrm{Y}$, Imanaka $\mathrm{K}$, Oshita $\mathrm{M}$, et al. Declining incidence of hepatocellular carcinoma in Osaka, Japan, from 1990 to 2003. Ann Intern Med. (2008) 148:820-6. doi: 10.7326/0003-4819-148-11-200806030-00004

57. Hung GY, Horng JL, Yen HJ, Lee CY, Lin LY. Changing incidence patterns of hepatocellular carcinoma among age groups in Taiwan. J Hepatol. (2015) 63:1390-6. doi: 10.1016/j.jhep.2015.07.032

58. Yeesoonsang S, McNeil E, Virani S, Bilheem S, Pittayawonganon C, Jiraphongsa C, et al. Trends in incidence of two major subtypes of liver and bile duct cancer: hepatocellular carcinoma and cholangiocarcinoma in Songkhla, Southern Thailand, 1989-2030. J Cancer Epidemiol. (2018) 2018:8267059. doi: 10.1155/2018/8267059

59. Carville KS, MacLachlan JH, Thursfield V, Cowie BC. Hepatocellular carcinoma over three decades in Victoria, Australia: epidemiology, diagnosis and trends, 1984-2013. Intern Med J. (2018) 48:835-44. doi: 10.1111/imj.13823

60. Chinnaratha MA, Graham C, Fraser RJL, Woodman RJ, Wigg AJ. Rising incidence of hepatitis B-related hepatocellular carcinoma in South Australia: 1996-2010. Intern Med J. (2016) 46:902-8. doi: 10.1111/imj.13121
61. Clark PJ, Stuart KA, Leggett BA, Crawford DH, Boyd P, Fawcett J, et al. Remoteness, race and social disadvantage: disparities in hepatocellular carcinoma incidence and survival in Queensland, Australia. Liver Int. (2015) 35:2584-94. doi: 10.1111/liv.12853

62. Thein HH, Walter SR, Gidding HF, Amin J, Law MG, George J, et al. Trends in incidence of hepatocellular carcinoma after diagnosis of hepatitis B or C infection: a population-based cohort study, 1992-2007. J Viral Hepat. (2011) 18:e232-41. doi: 10.1111/j.1365-2893.2011.01440.x

63. Wallace MC, Preen DB, Short MW, Adams LA, Jeffrey GP. Hepatocellular carcinoma in Australia 1982 to 2014: increasing incidence and improving survival. Liver Int. (2018) 39:522-30. doi: 10.1111/liv.13966

64. Patel N, Benipal B. Incidence of cholangiocarcinoma in the USA from 2001 to 2015: a US Cancer Statistics Analysis of 50 States. Cureus. (2019) 11:e3962. doi: 10.7759/cureus.3962

65. Saha SK, Zhu AX, Fuchs CS, Brooks GA. Forty-year trends in cholangiocarcinoma incidence in the U.S.: intrahepatic disease on the rise. Oncologist. (2016) 21:594-9. doi: 10.1634/theoncologist.2015-0446

66. Van Dyke AL, Shiels MS, Jones GS, Pfeiffer RM, Petrick JL, BeebeDimmer JL, et al. Biliary tract cancer incidence and trends in the United States by demographic group, 1999-2013. Cancer. (2019) 125:1489-98. doi: $10.1002 / \mathrm{cncr} .31942$

67. Kim BW, Oh CM, Choi HY, Park JW, Cho H, Ki M. Incidence and overall survival of biliary tract cancers in South Korea from 2006 to 2015: Using the National Health Information Database. Gut Liver. (2019) 13:104-13. doi: $10.5009 /$ gnl18105

68. Shin HR, Oh JK, Lim MK, Shin A, Kong HJ, Jung KW, et al. Descriptive epidemiology of cholangiocarcinoma and clonorchiasis in Korea. J Korean Med Sci. (2010) 25:1011-6. doi: 10.3346/jkms.2010.25.7.1011

69. Kamsa-ard S, Wiangnon S, Suwanrungruang K, Promthet S, Khuntikeo N, Kamsa-ard S, et al. Trends in liver cancer incidence between 1985 and 2009, Khon Kaen, Thailand: cholangiocarcinoma. Asian Pac J Cancer Prev. (2011) 12:2209-13.

70. Witjes CD, Karim-Kos HE, Visser O, de Vries E, IJzermans JN, de Man RA, et al. Intrahepatic cholangiocarcinoma in a low endemic area: rising incidence and improved survival. HPB. (2012) 14:777-81. doi: 10.1111/j.1477-2574.2012.00536.x

71. Wang J, Li E, Yang H, Wu J, Lu HC, Yi C, et al. Combined hepatocellularcholangiocarcinoma: a population level analysis of incidence and mortality trends. World J Surg Oncol. (2019) 17:43. doi: 10.1186/s12957-019-1586-8

72. Weber SM, Ribero D, O’Reilly EM, Kokudo N, Miyazaki M, Pawlik TM. Intrahepatic cholangiocarcinoma: expert consensus statement. HPB. (2015) 17:669-80. doi: 10.1111/hpb.12441

73. Sayiner M, Golabi P, Younossi ZM. Disease burden of hepatocellular carcinoma: a global perspective. Dig Dis Sci. (2019) 64:910-7. doi: 10.1007/s10620-019-05537-2

74. Kim HS, El-Serag HB. The epidemiology of hepatocellular carcinoma in the USA. Curr Gastroenterol Rep. (2019) 21:17. doi: 10.1007/s11894-019-0681-x

75. Cooke GS, Andrieux-Meyer I, Applegate TL, Atun R, Burry JR, Cheinquer H, et al. Accelerating the elimination of viral hepatitis: a lancet gastroenterology \& hepatology Commission. Lancet Gastroenterol Hepatol. (2019) 4:135-84. doi: 10.1016/S2468-1253(18)30412-6

76. Kanwal F, Kramer J, Asch SM, Chayanupatkul M, Cao Y, El-Serag HB. Risk of hepatocellular cancer in HCV patients treated with directacting antiviral agents. Gastroenterology. (2017) 153:996-1005.e1. doi: 10.1053/j.gastro.2017.06.012

77. Moon AM, Singal AG, Tapper EB. Contemporary epidemiology of chronic liver disease and cirrhosis. Clin Gastroenterol Hepatol. (2019). doi: 10.1016/j.cgh.2019.07.060. [Epub ahead of print].

78. Chuang SC, Lee YC, Wu GJ, Straif K, Hashibe M. Alcohol consumption and liver cancer risk: a meta-analysis. Cancer Causes Control. (2015) 26:1205-31. doi: 10.1007/s10552-015-0615-3

79. European Association for the study of the liver, European Organisation for research and treatment of cancer. EASL-EORTC clinical practice guidelines: management of hepatocellular carcinoma. J Hepatol. (2012) 56:908-43. doi: 10.1016/j.jhep.2011.12.001

80. Marrero JA, Kulik LM, Sirlin CB, Zhu AX, Finn RS, Abecassis MM, et al. Diagnosis, staging, and management of hepatocellular carcinoma: 2018 
practice guidance by the American Association for the Study of Liver Diseases. Hepatology. (2018) 68:723-50. doi: 10.1002/hep.29913

81. Alavi M, Law MG, Valerio H, Grebely J, Amin J, Hajarizadeh B, et al. Declining hepatitis $\mathrm{C}$ virus-related liver disease burden in the direct-acting antiviral therapy era in New South Wales, Australia. J Hepatol. (2019) 71:281-8. doi: 10.1016/j.jhep.2019.04.014

82. Younossi ZM, Koenig AB, Abdelatif D, Fazel Y, Henry L, Wymer M. Global epidemiology of nonalcoholic fatty liver disease-Meta-analytic assessment of prevalence, incidence, and outcomes. Hepatology. (2016) 64:73-84. doi: $10.1002 /$ hep. 28431

83. NCD Risk Factor Collaboration. Trends in adult body-mass index in 200 countries from 1975 to 2014: a pooled analysis of 1698 population-based measurement studies with 19.2 million participants. Lancet. (2016) 387:137796. doi: 10.1016/S0140-6736(16)30054-X

84. Younossi ZM, Stepanova M, Younossi Y, Golabi P, Mishra A, Rafiq N, et al. Epidemiology of chronic liver diseases in the USA in the past three decades. Gut. (2019) 69:564-8. doi: 10.1136/gutjnl-2019-318813

85. NCD Risk Factor Collaboration. Worldwide trends in diabetes since 1980: a pooled analysis of 751 population-based studies with 4.4 million participants. Lancet. (2016) 387:1513-30. doi: 10.1016/S0140-6736(16)00618-8

86. Younossi Z, Anstee QM, Marietti M, Hardy T, Henry L, Eslam M, et al. Global burden of NAFLD and NASH: trends, predictions, risk factors and prevention. Nat Rev Gastroenterol Hepatol. (2018) 15:11-20. doi: 10.1038/nrgastro.2017.109

87. Heffernan A, Cooke GS, Nayagam S, Thursz M, Hallett TB. Scaling up prevention and treatment towards the elimination of hepatitis
C: a global mathematical model. Lancet. (2019) 393:1319-29. doi: 10.1016/S0140-6736(18)32277-3

88. Siegel RL, Miller KD, Jemal A. Cancer statistics, 2019. CA Cancer J Clin. (2019) 69:7-34. doi: 10.3322/caac.21551

89. Lazo M, Nwankwo C, Daya NR, Thomas DL, Mehta SH, Juraschek S, et al. Confluence of epidemics of hepatitis C, diabetes, obesity, and chronic kidney disease in the United States Population. Clin Gastroenterol Hepatol. (2017) 15:1957-64.e7. doi: 10.1016/j.cgh.2017.04.04690

90. Global Burden of Disease Liver Cancer C, Akinyemiju T, Abera S, Ahmed M, Alam N, Alemayohu MA, et al. The burden of primary liver cancer and underlying etiologies from 1990 to 2015 at the global, regional, and national level: results from the global burden of disease study 2015. JAMA Oncol. (2017) 3:1683-91. doi: 10.1001/jamaoncol.20 17.3055

Conflict of Interest: The authors declare that the research was conducted in the absence of any commercial or financial relationships that could be construed as a potential conflict of interest.

Copyright (C) 2020 Dasgupta, Henshaw, Youlden, Clark, Aitken and Baade. This is an open-access article distributed under the terms of the Creative Commons Attribution License (CC BY). The use, distribution or reproduction in other forums is permitted, provided the original author(s) and the copyright owner(s) are credited and that the original publication in this journal is cited, in accordance with accepted academic practice. No use, distribution or reproduction is permitted which does not comply with these terms. 